\title{
Efficiency of Moxifloxacin in the Treatment of Helicobacter pylori Infection
}

\author{
Battal Altun* and Kadir Ozturk ${ }^{\dagger}$ \\ ${ }^{*}$ Department of Internal Medicine, Kasımpasa Military Hospital, Istanbul, and ${ }^{\dagger}$ Department of Gastroenterology, Gulhane School of Medicine, \\ Ankara, Turkey
}

\section{To the Editor:}

We read the article of Chung et al.," "The efficacy of moxifloxacin-containing triple therapy after standard triple, sequential, or concomitant therapy failure for Helicobacter pylori eradication in Korea" with great interest. In this very welldesigned study, the authors found that the eradication rate with moxifloxacin-containing triple therapy was lower than that of bismuth-containing quadruple therapy. These authors speculated that the failure of moxifloxacin-containing triple therapy in this study was primarily due to moxifloxacin resistance. These findings provide new information regarding moxifloxacin resistance to Helicobacter pylori. However, we believe that some points that should be emphasized in the study.

First, in the first part of the methods section, the authors reported that the rapid urease test or histology was used for the initial diagnosis of $H$. pylori. However, in the third part of the methods section, the authors noted that both histology and a rapid urease test were performed to identify the presence of $H$. pylori infection. It is not clear which methods were used for the initial diagnosis of $H$. pylori in this study. We know that the American College of Gastroenterology guidelines on the management of $H$. pylori infection recommend using at least two different tests for the diagnosis of $H$. pylori, except culture. ${ }^{2}$

Second, in the discussion section, the authors concluded that bismuth-containing quadruple therapy was more effective than moxifloxacin-containing triple therapy as a second-line therapy after failed first-line therapy. When the results of $H$. pylori eradication were assessed in detail, the eradication rate of moxifloxacin-containing triple therapy after concomitant or sequential therapy was $67 \%$, and the eradication rate of moxifloxacin-containing triple therapy after standard triple therapy was 50\%. However, the success rate of moxifloxacin-containing triple therapy after standard triple therapy was expected to be greater because sequential and concomitant therapy is more po- tent than standard triple therapy. This result is controversial. We believe that moxifloxacin-containing therapy should be 14 days because, in another Korean study, Lee et al. ${ }^{3}$ reported that the eradication rate of the 14-day moxifloxacin-based triple regimen was 73.5\%, while that of the 7-day regimen was 53.1\%.

In addition, in the results section of the paper, there were conflicting data regarding the number of patients who were treated with moxifloxacin-containing triple therapy as a second-line treatment. Moreover, in the study design section of the paper, the authors specified that all of the patients who received sequential therapy or concomitant therapy as a first-line regimen received bismuth-containing quadruple therapy as a second-line regimen. However, in the present study, moxifloxacin-containing therapy was used as a second-line therapy after sequential or concomitant therapy.

Consequently, we conclude that before making certain interpretations, this work should be reconsidered in light of the above-mentioned suggestions. These considerations could provide the readers of the journal clearer information regarding the efficiency of moxifloxacin in the treatment of $H$. pylori infection.

\section{CONFLICTS OF INTEREST}

No potential conflict of interest relevant to this article was reported.

\section{REFERENCES}

1. Chung KH, Lee DH, Jin E, et al. The efficacy of moxifloxacincontaining triple therapy after standard triple, sequential, or concomitant therapy failure for Helicobacter pylori eradication in Korea. Gut Liver 2014;8:605-611.

2. Chey WD, Wong BC; Practice Parameters Committee of the

Correspondence to: Battal Altun

Department of Internal Medicine, Kasımpasa Military Hospital, Yesilkoy, Istanbul 34149, Turkey

Tel: +90-5415429657, E-mail: battalaltun@yahoo.com

Received on November 30, 2014. Revised on January 6, 2015. Accepted on January 7, 2015. Published online June 19, 2015 pISSN 1976-2283 eISSN 2005-1212 http://dx.doi.org/10.5009/gnl14469

() This is an Open Access article distributed under the terms of the Creative Commons Attribution Non-Commercial License (http://creativecommons.org/licenses/by-nc/4.0) which permits unrestricted non-commercial use, distribution, and reproduction in any medium, provided the original work is properly cited. 
810 Gut and Liver, Vol. 9, No. 6, November 2015

American College of Gastroenterology. American College of Gastroenterology guideline on the management of Helicobacter pylori infection. Am J Gastroenterol 2007;102:1808-1825.

3. Lee ST, Lee DH, Lim JH, et al. Efficacy of 7-day and 14-day bismuth-containing quadruple therapy and 7-day and 14-day moxifloxacin-based triple therapy as second-line eradication for Helicobacter pylori infection. Gut Liver 2015;9:478-485. 